\title{
Autoignited Lifted Flames of Dimethyl Ether in Heated Coflow Air
}

\author{
Saeed M. Al-Noman ${ }^{1}$, Byung Chul Choi ${ }^{2}$, Suk Ho Chung ${ }^{3 *}$ \\ ${ }^{1}$ Saudi Electricity Company \\ Research and Development Department \\ Riyadh, Saudi Arabia \\ ${ }^{2}$ Korean Register of Shipping \\ Research and Development Center \\ Busan, Republic of Korea \\ ${ }^{3}$ King Abdullah University of Science and Technology (KAUST) \\ Clean Combustion Research Center (CCRC) \\ Thuwal, Saudi Arabia
}

* Corresponding author

Suk Ho Chung

Clean Combustion Research Center

King Abdullah University of Science and Technology

Thuwal, Saudi Arabia

E-mail: sukho.chung@kaust.edu.sa 


\title{
Autoignited Lifted Flames of Dimethyl Ether in Heated Coflow Air
}

\author{
Saeed M. Al-Noman ${ }^{1}$, Byung Chul Choi ${ }^{2}$, Suk Ho Chung ${ }^{3 *}$ \\ ${ }^{1}$ Saudi Electricity Company \\ Research and Development Department \\ Riyadh, Saudi Arabia \\ ${ }^{2}$ Korean Register of Shipping \\ Research and Development Center \\ Busan, Republic of Korea \\ ${ }^{3}$ King Abdullah University of Science and Technology (KAUST) \\ Clean Combustion Research Center (CCRC) \\ Thuwal, Saudi Arabia
}

\begin{abstract}
Autoignited lifted flames of dimethyl ether (DME) in laminar nonpremixed jets with hightemperature coflow air have been studied experimentally. When the initial temperature was elevated to over $860 \mathrm{~K}$, an autoignition occurred without requiring an external ignition source. A planar laser-induced fluorescence (PLIF) technique for formaldehyde $\left(\mathrm{CH}_{2} \mathrm{O}\right)$ visualized qualitatively the zone of low temperature kinetics in a premixed flame. Two flame configurations were investigated; (1) autoignited lifted flames with tribrachial edge having three distinct branches of a lean and a rich premixed flame wings with a trailing diffusion flame and (2) autoignited lifted flames with mild combustion when the fuel was highly diluted. For the autoignited tribrachial edge flames at critical autoignition conditions, exhibiting repetitive extinction and re-ignition phenomena near a blowout condition, the characteristic flow time (liftoff height scaled with jet velocity) was correlated with the square of the ignition delay time of the stoichiometric mixture. The liftoff heights were also correlated as a function of jet velocity times the square of ignition delay time. Formaldehydes were observed between the fuel nozzle and the lifted flame edge, emphasizing a low-temperature kinetics for autoignited lifted flames, while for a non-autoignited lifted flame, formaldehydes were observed near a thin luminous flame zone.

For the autoignited lifted flames with mild combustion, especially at a high temperature, a unique non-monotonic liftoff height behavior was observed; decreasing and then increasing liftoff height with jet velocity. This behavior was similar to the binary mixture fuels of $\mathrm{CH}_{4} / \mathrm{H}_{2}$ and $\mathrm{CO} / \mathrm{H}_{2}$ observed previously. A transient homogeneous autoignition analysis suggested that such decreasing behavior with jet velocity can be attributed to partial oxidation characteristics of DME in producing appreciable amounts of $\mathrm{CH}_{4} / \mathrm{CO} / \mathrm{H}_{2}$ ahead of the edge flame region.
\end{abstract}




\section{Introduction}

Dimethylether (DME) is an oxygenated fuel which has drawn attention recently for various applications such as automotive engines because of its low particulate emission and high cetane number characteristics, suitable for compression ignition engines. DME can be produced from natural gas. For small/medium natural gas wells, conversion of methane into DME can be economical for transportation, considering compression and evaporation of natural gas during transportation processes. DME can also be produced through coal gasification.

The autoignition temperature of DME is $508 \mathrm{~K}$ [1], which is very low compared to other hydrocarbons including methane. Thus, DME can be a candidate as an ignition improver [2-6]. DME fuel exhibits negative temperature coefficient (NTC) region which is attributed to twostage ignition, and features an increase in ignition delay time as temperature increases. Various studies investigated this phenomenon at high pressure conditions [7-9]. Ignition delay times representing fuel reactivity have been measured experimentally [10-14] and kinetic mechanisms have been developed [15-21] to be utilized in numerical simulations.

Ignition delay times are typically measured for homogeneous mixtures in shock tubes and rapid compression machines. While typical autoignition in practical combustion systems such as in diesel and premixed charge compression ignition engines occurs under inhomogeneous conditions. However, studies on the relation between ignition delay times measured under homogeneous conditions and autoignition phenomena under inhomogeneous conditions are limited. Recently, a canonical jet configuration was adopted to investigate the relation between chemical ignition delay time and physical flow time by studying the characteristics of autoignited laminar lifted jet flames in high-temperture coflow air for various hydrocarbon fuels [22-27]. The autoignited lifted flames exhibited two distinct structures: tribrachial edge and mild combustion. In the autoignited lifted flame with tribrachial edge, three distinct branches of a lean and a rich premixed flame wings along with a trailing diffusion flame are exhibited, all extending from a tribrachial point [28-30]. The autoignited lifted flame with mild 
combustion structure with highly diluted fuel is characterized by its faint blue luminosity $[22,31]$. Such a flame is characterized as the initial temperature $T_{0}$ is larger than the autoignition temperature and $\left(T_{\mathrm{f}}-T_{0}\right)<T_{0}$, where $T_{\mathrm{f}}$ is the flame temperature, corresponding to the enthalpy increase by heat release is smaller than the initial enthalpy [31]. For both flame structures, the ignition delay time was found to be a key parameter for the stabilization of autoignited lifted flames [22-23]. Recently, autoignition characteristics of lifted laminar jet flames of DME have been studied numerically at elevated pressures and temperatures [32-34], revealing a unique polybrachial flame structure, which is attributed to the role of methoxymethylperoxy8 radical $\left(\mathrm{CH}_{3} \mathrm{OCH}_{2} \mathrm{O}_{2}\right)$ in DME combustion. However, a systematic experimental study of DME flames under autoignition conditions in jet configuration has not been conducted yet.

Formaldehyde $\left(\mathrm{CH}_{2} \mathrm{O}\right)$ is an important intermediate species which is formed at early stage of ignition processes through a low-temperature oxidation pathway, which can be visualized by adopting a laser-induced fluorescence (LIF) technique. Thus, a $\mathrm{CH}_{2} \mathrm{O}$ PLIF measurement could provide a progress of autoignition process. Several $\mathrm{CH}_{2} \mathrm{O}-\mathrm{LIF}$ studies have been conducted for various flame configurations including premixed flames [35], non-premixed flames [36], channel-flow catalytic reactor [37], and homogeneous charge compression [38]. The combination of OH-LIF and $\mathrm{CH}_{2} \mathrm{O}$-LIF images has been utilized to identify the flame heat release region [39].

In the present study, autoignited laminar lifted flames of DME with high-temperature coflow air are studied experimentally at the atmospheric pressure condition. This fuel is selected since it is an oxygenated fuel with strong low temperature kinetics, unlike other hydrocarbon fuels investigated previously [22-26]. The structure of DME lifted flame and $\mathrm{CH}_{2} \mathrm{O}$ PLIF measurement are conducted. The liftoff heights of autoignited DME flames are analyzed and the role of ignition delay time is investigated. A unique behavior, having a decreasing liftoff height with increasing jet velocity, is reported. Such behavior was never observed for autoignited lifted flames with single component hydrocarbon fuels, while it was 
observed for binary mixture fuels of $\mathrm{CO} / \mathrm{H}_{2}$ and $\mathrm{CH}_{4} / \mathrm{H}_{2}$ [24,40]. Partial oxidation characteristics of DME fuel is discussed to explain such a behavior.

\section{Experiment}

The apparatus consisted of a coflow burner, a flow control system, a heater assembly, and a planar laser-induced fluorescence (PLIF) setup, as schematically shown in Fig. 1. Details of the burner have been reported previously [22]. A stainless-steel fuel nozzle with the inner diameter of $d=3.76 \mathrm{~mm}$ was placed at the center of the coflow burner. Its length was $750 \mathrm{~mm}$ for the flow to be fully developed. A metal fiber, ceramic beads, and a honeycomb were utilized to ensure flow uniformity of the coflow air whose diameter is $133 \mathrm{~mm}$. To minimize the heat loss, a ceramic cylindrical insulator was placed around the air coflow as a confinement, whose length was $500 \mathrm{~mm}$ with the outer diameter of $300 \mathrm{~mm}$. For a visualization purpose, three quartz windows were installed.

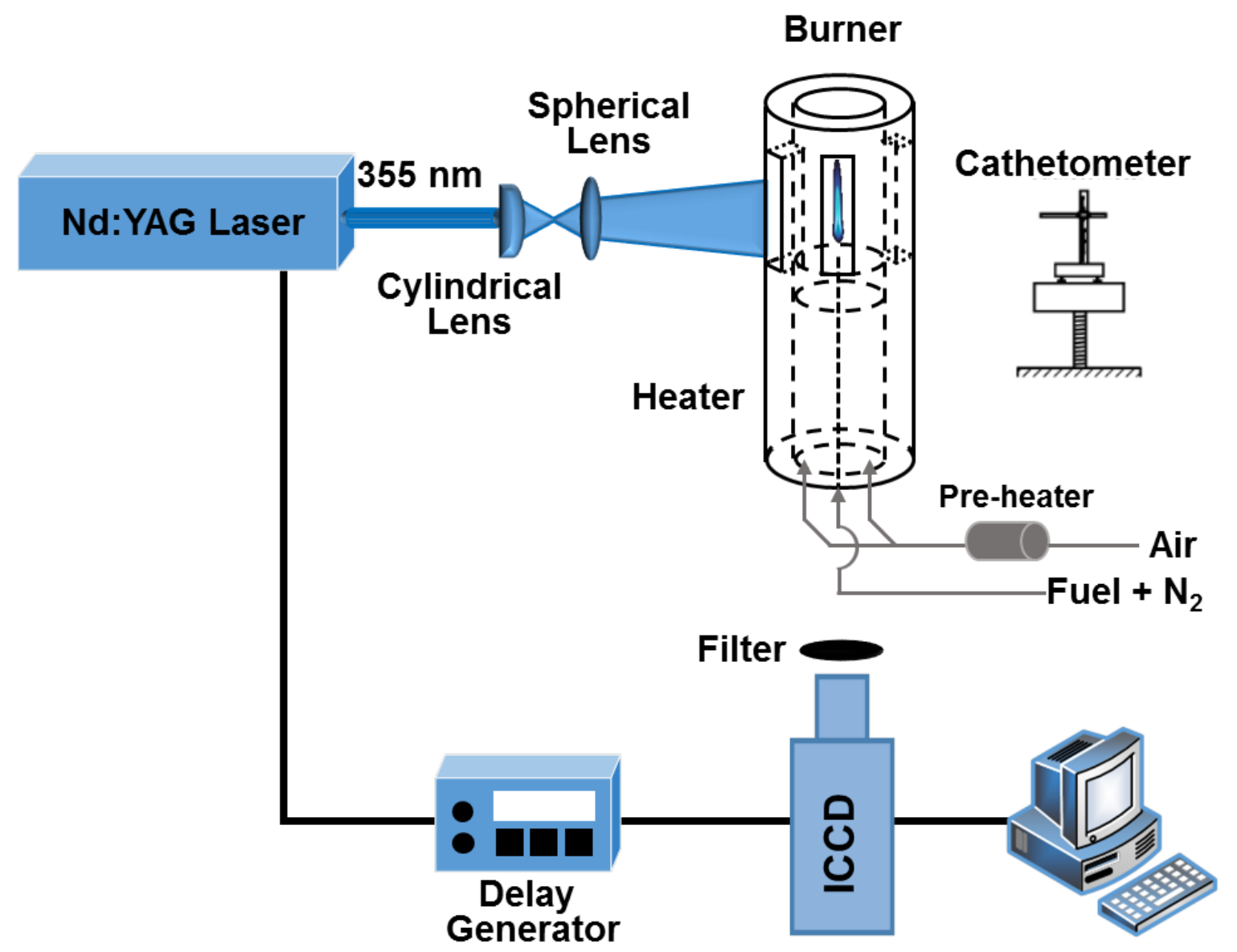


Figure 1. Schematic of experimental setup.

The fuels were supplied through a mixer filled with glass beads for homogeneous mixing of fuel and nitrogen diluent, which were chemically pure grade of DME $(>99.60 \%)$ and nitrogen $(>99.99 \%)$. Propane fuel $(>99.95 \%)$, exhibiting weak low temperature kinetics, was also used for a comparison in the PLIF measurement. Compressed air was used for the coflow. Gas flow rates were metered by mass flow controllers.

The heating system had a pre-heater and a main heater to control coflow air temperature. The air passed through the pre-heater with star-wound shape first and then the preheated air was supplied to the ceramic heater, which also served as the inner surface of the burner body. Heat exchange between the heated coflow air and the fuel nozzle occurred inside the ceramic insulator. The temperatures of the heated air and fuel were measured at the exit of the coaxial nozzle and fuel nozzle exit, respectively, with sheathed K-type thermocouples. The temperature difference between the air and fuel was less than $10 \mathrm{~K}$, such that the fuel temperature could be regarded as the same as the coflow air temperature. Details of the effect of radiation in the thermocouple measurement were discussed previously [22-26], which was negligibly small in the initial temperature measurement, typically less than $1000 \mathrm{~K}$.

The coflow velocity was fixed at $V_{\mathrm{CO}}=1.1 \mathrm{~m} / \mathrm{s}$ to maintain a uniform temperature up to the edges of lifted flames. Details about temperature uniformity have been reported previously [22-26]. Liftoff heights were measured by a cathetometer.

For the PLIF measurement of $\mathrm{CH}_{2} \mathrm{O}$, a third-harmonic of Nd:YAG laser (Quantel, Brilliant) was used to excite formaldehyde at $355 \mathrm{~nm}$ (rotational transitions within the $\tilde{A}^{1} A_{2}$ $X^{1} A_{1} 4_{0}^{1}$ vibronic manifold) [41]. The $6 \mathrm{~mm}$-diameter UV pulsed laser beam $(10 \mathrm{~Hz})$ was supplied with an energy of $170 \mathrm{~mJ} /$ pulse to ensure an excitation of formaldehyde. Then, the beam was expanded to form a thin laser sheet $\left(3 \mathrm{~cm}\right.$ width) for visualizing a $2 \mathrm{D}$ image of $\mathrm{CH}_{2} \mathrm{O}$ PLIF. This was accomplished by combining plano-convex cylindrical and spherical UV fused 
silica lenses with focal lengths of 15 and $75 \mathrm{~cm}$, respectively. The formaldehyde fluorescence was detected using an ICCD camera (Princeton Instrument) with a UV lens, together with a combination of long- and short-pass filters $(400-450 \mathrm{~nm})$ placed in front of the camera to collect the formaldehyde fluorescence. This broadband absorption-detection was selected to ensure high formaldehyde signal $[41,42]$. The interference of PAH fluorescence can be neglected because they are saturated at high laser excitation energy while the formaldehyde fluorescence is expected to be in the linear regime [41,42]. The number of accumulated single shot images was fixed at 20 for all cases to compare the qualitative $\mathrm{CH}_{2} \mathrm{O}$ intensities for different cases. The excitation laser energy/pulse was fixed for all cases. The laser system and camera were synchronized using a delay generator and a computer software. A digital camera was used to capture visible images of flames.

\section{Results and Discussion}

Various experiments have been conducted previously to study the effect of elevated initial temperatures in jet flames with coflow air for hydrocarbon fuels [22-26]. At relatively low initial temperatures, stable lifted flames for methane, ethane, and ethylene did not exist because such a flame is unstable as the Schmidt number $(\mathrm{Sc})$ of fuel is less than unity [23], whereas non-autoignited lifted flames were stable for gaseous fuels with $\mathrm{Sc}>1$ such as propane, nbutane and pre-vaporized liquid fuels of n-heptane and iso-octane [22-26]. In the present experiment, stable non-autoignited lifted flames of DME fuel were observed as its Schmidt number being larger than unity. When the initial temperature was elevated to a high temperature above an autoignition temperature, autoignited lifted flames were stable regardless of the fuel Schmidt number [23].

Extensive studies have been conducted for non-autoignited lifted flames previously [2230]. Their stabilization characteristics have been identified as the balance mechanism between the propagation speed of tribrachial edge flame and local flow velocity. Therefore, we will 
focus in the present study on autoignited lifted flames of DME fuel.

\subsection{Visualization and $\mathrm{CH}_{2} \mathrm{O}$ structure in lifted flames}

Figure 2 shows visible images and $\mathrm{CH}_{2} \mathrm{O}$ PLIF images of several lifted flames for DME (a-c) for non-autoignited flames at the initial temperatures $T_{0}=294 \mathrm{~K}$ and autoignited flames $\left(T_{0}=900 \mathrm{~K}\right.$. For comparison, propane (d-f) flames are also tested, since propane is a representative gaseous alkane fuel with weak low-temperature kinetics and DME is an oxygenated fuel (ether) exhibiting strong low-temperature kinetics. The molecular weights for propane and DME are similar (44 and 46, respectively), which results in reasonably matched characteristic diffusion time scales. Note that fuel diffusivity (or the Schmidt number) played an important role for lifted flame stabilization for non-autoignited flames. Here, the fuel mole fraction $X_{\mathrm{F}, 0}$ and the fuel jet velocity $U_{0}$ were adjusted for the flame to be located within the laser sheet for the PLIF measurement. For each pair (Figs. 2a-d and 2b-e), the characteristic flow times were also reasonably matched, since the liftoff heights and jet velocities are reasonably similar. For the autoignited mild combustion cases (Figs. 2c and $2 \mathrm{f}$ at $900 \mathrm{~K}$ ), only the diffusion time scales and liftoff heights are reasonably matched, since the condition for the existence of such flames are quite different between these two fuels, such that the velocities cannot be reasonably matched. 


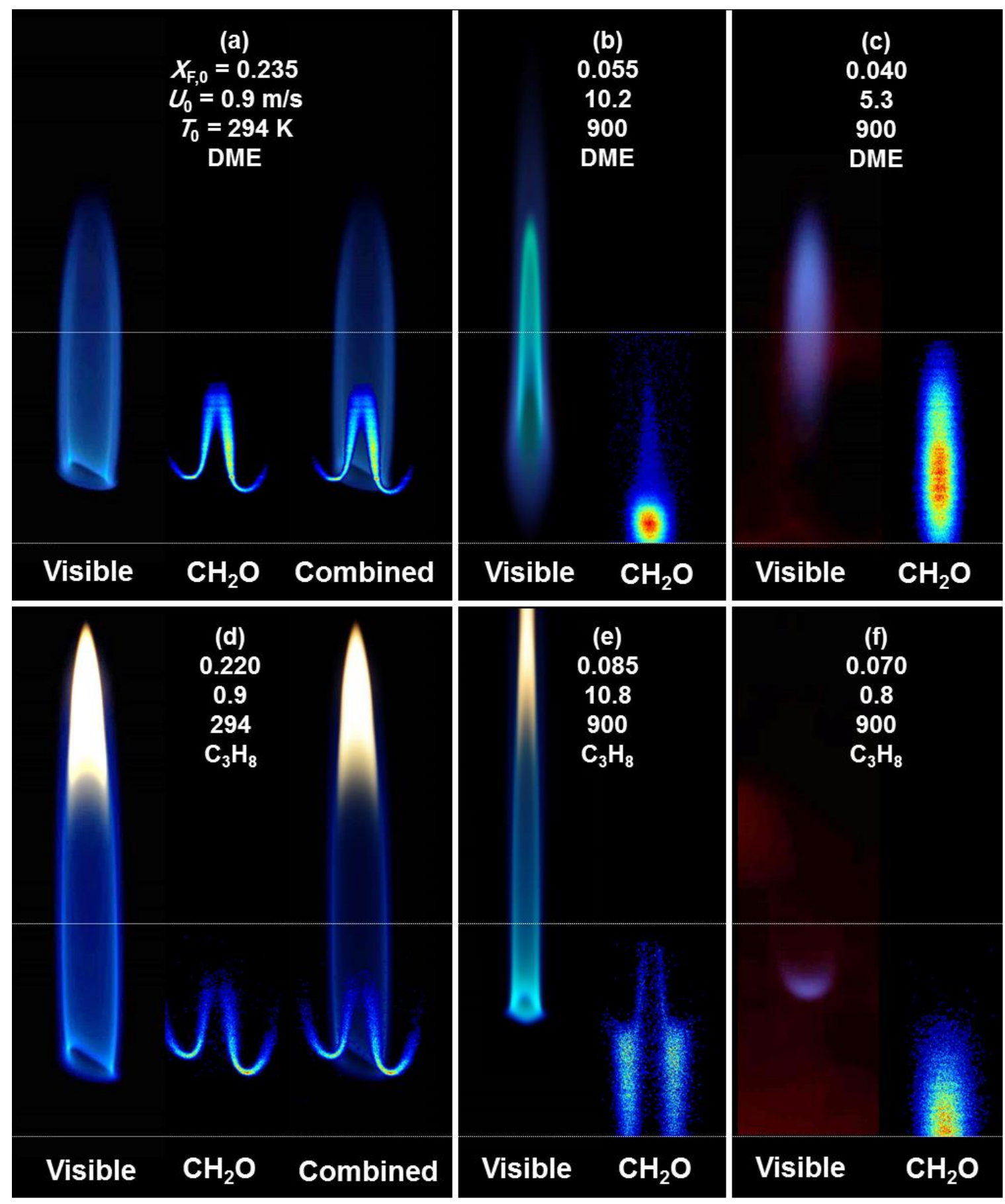

Figure 2. Visible images and $\mathrm{CH}_{2} \mathrm{O}$ PLIF images for non-autoignited and autoignited lifted flames of DME (a-c) and propane (d-f).

When $T_{0}<860 \mathrm{~K}$, an external ignition source was required to form a flame, while autoignited lifted flames were generated at higher initial temperatures. Here, the PLIF images represent qualitative $\mathrm{CH}_{2} \mathrm{O}$ concentrations. The dotted-lines indicate the laser window for PLIF imaging. 
First, for non-autoignited lifted flames of DME (a) and propane (d), the flame bases exhibit tribrachial edge structures. Although somewhat unclear from the visible images, the structure can be clearly identified by the naked eyes and also from the combined images of visible images (showing long diffusion flames) and $\mathrm{CH}_{2} \mathrm{O}-\mathrm{PLIF}$ signals (showing premixed flame wings) [36] which are confined to premixed flame wings. Another observation is that $\mathrm{CH}_{2} \mathrm{O}$ fluorescence cannot be observed in the cold region between the flame edge and the fuel nozzle indicating that this region can be considered non-reactive [43]. Note that the $\mathrm{CH}_{2} \mathrm{O}$ fluorescence of propane case is somewhat weaker than DME, which can be attributed to the fact that DME is an oxygenated fuel and formaldehyde can be formed with higher concentrations for DME than for propane. This point will further be discussed later. The visible images are somewhat skewed near the base at small jet velocity case of the non-autoignited flames, which can be partially attributed to non-uniformity by the round fuel tube and an array of small rectangular honeycomb.

For the autoignited lifted flames with tribrachial edge (Fig. $2 \mathrm{~b}$ and e), the images show high-intensity $\mathrm{CH}_{2} \mathrm{O}$ signals in the region far upstream of the lifted flame edge, indicating nonnegligible reaction in the upstream regions of the flame edges leading to autoignition. Because of mixing prior to flame stabilization zone, a partial oxidation of DME can be a source of formaldehyde existing in this region. Comparing the cases of DME and propane, the formaldehyde PLIFs show different shapes. The maximum signals along the radial direction are along the centerline for the DME, while are along the mixing layer in the upstream of the flame base for the propane, having much weaker signals as compared with the DME case. The maximum PLIF signal for propane (e) is about 0.43 times the maximum for DME (b). The stronger formaldehyde signal for the DME case can be explained as DME fuel can go through partial oxidation at much lower temperature than alkane fuels. Interestingly, the formaldehyde signal of propane autoignited lifted flame shows a similar shape as the autoignited methane lifted flame case in the computational results in a previous study [44], although for methane 
autoignited lifted flames, the $\mathrm{CH}_{2} \mathrm{O}$ signals are too weak to be detected in the present experimental setup.

The flame structure for the autoignited lifted flames with mild combustion are shown in Figs. $2 \mathrm{c}$ and $2 \mathrm{f}$ for the highly diluted DME and propane compared to cases (a) and (d), respectively. The flames exhibit faint blue color, without having distinct tribrachial structures. Similar to the autoignited lifted flames with tribrachial edge, the formaldehyde signal exists in the upstream regions of the lifted flame edges. The autoignited lifted flame with mild combustion for propane (f) shows similar profile as the DME case but with weaker intensity. The maximum signal along the radial direction occurs along the centerline for both the DME and propane cases. This can be attributed to a long residence time since the jet velocity is very low $(0.8 \mathrm{~m} / \mathrm{s})$ for the propane as compared with the DME case of $5.3 \mathrm{~m} / \mathrm{s}(\mathrm{c})$, such that much longer time is available for partial oxidation of propane. The maximum PLIF signal for propane (f) is about 0.46 times the maximum for DME (c), which is 1.21 times the maximum for DME (b) with the autoignited tribrachial edge. The existence of formaldehyde signal in the upstream regions of autoignited lifted flames demonstrates the importance of low temperature kinetics in forming formaldehyde leading to an autoignition behavior.

The existence of autoignited lifted flames of tribrachial edge and mild combustion can be classified based on the initial temperature and fuel mole fraction [22,23]. Figure 3 shows the mapping of autoignition regimes in terms of these two parameters. Each symbol represents the combustion mode observed, including no autoignition (No-auto), autoignited lifted flame with tribrachial edge (A-Tri), autoignited lifted flame with mild combustion (A-Mild), and transition to turbulence (TT) where a laminar lifted flame cannot be observed. Between the two regimes of A-Tri and A-Mild, there exists a transition regime, similar to other hydrocarbon fuels [2226]. The cross symbol indicates that even though mild combustion is observed, liftoff heights are not measured since they are located outside of the uniform temperature region. The boundaries are approximate distinguishing different flame modes_based on the observation. 


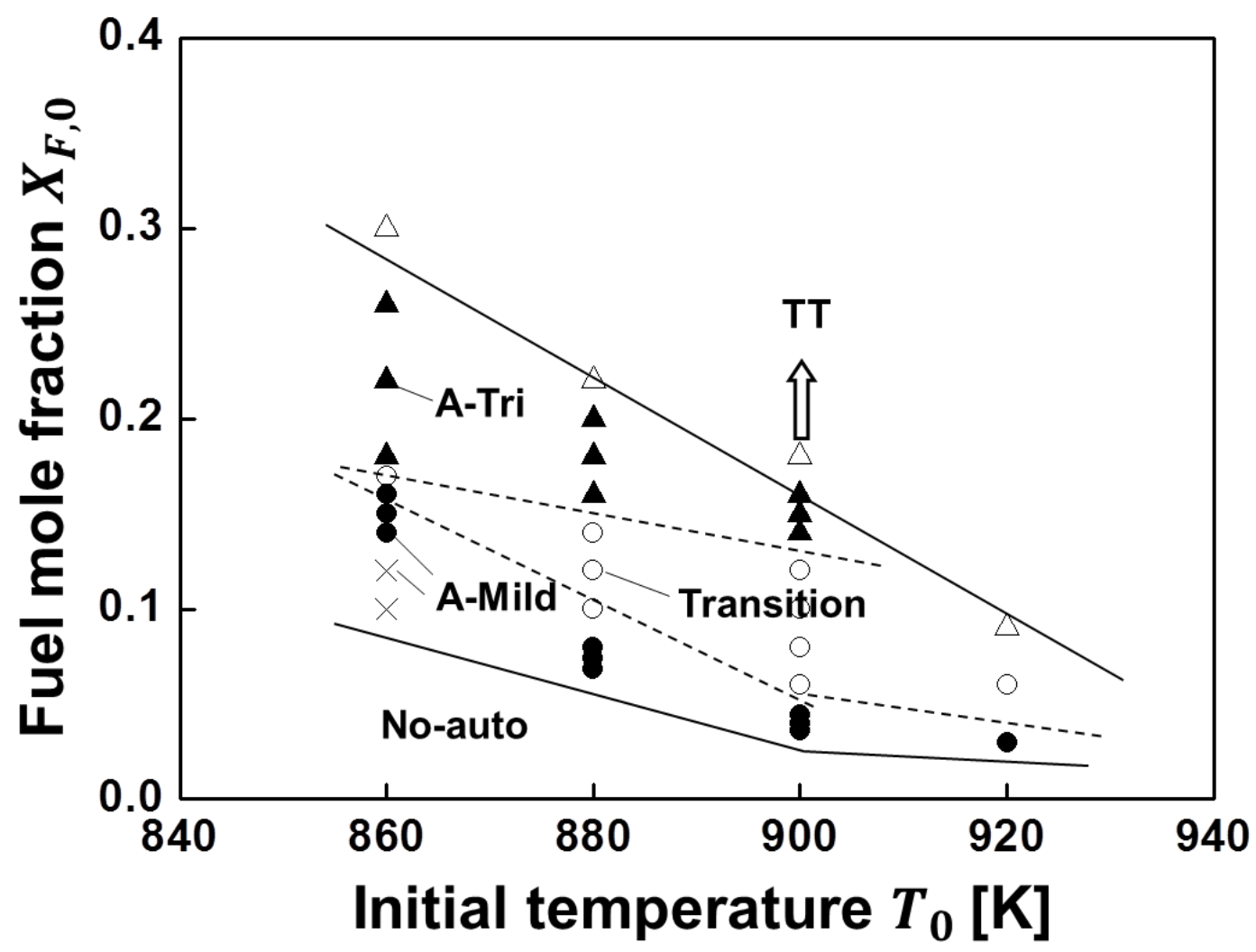

Figure 3. Autoignition regimes of DME in terms of initial temperature and fuel mole fraction. Symbols indicate the modes of no-autoignition (No-auto), autoignited tribrachial (A-Tri; solid triangle), autoignited mild (A-Mild; solid circle and cross (outside of measurement range)), transition (from tribrachial to mild combustion; open circle), transition to turbulence(TT; open triangle).

The autoignited lifted flames can be first observed at $T_{0}=860 \mathrm{~K}$ in the present experimental setup. This temperature is much higher than the autoignition temperature of DME $(508 \mathrm{~K})[1]$, which can be attributed to the high level of fuel dilution and inhomogeneous jet configuration. The autoignited lifted flames with tribrachial edge can be featured for relatively high fuel mole fractions and within specific initial temperature range. For lower fuel mole fractions, autoignited lifted flames with mild combustion can be observed. If both fuel mole fraction and initial temperature are very high, a transition to turbulent flame occurred. Our focus here will be on laminar lifted flames. 


\subsection{Liftoff heights of autoignited flames with tribrachial edge structure}

The liftoff height characteristics of the autoingited DME flames with tribrachial edges are shown in Fig. 4 as a function of jet velocity at several initial temperatures. The result shows that the liftoff height $H_{\mathrm{L}}$ increases with jet velocity and is longer at lower temperature. In the $\log -\log$ scale, this increase is reasonably linear for the relatively low temperature cases $\left(T_{0}=\right.$ 860 and $880 \mathrm{~K}$ ). Such a linear trend is consistent with previous results for various fuels [2226].

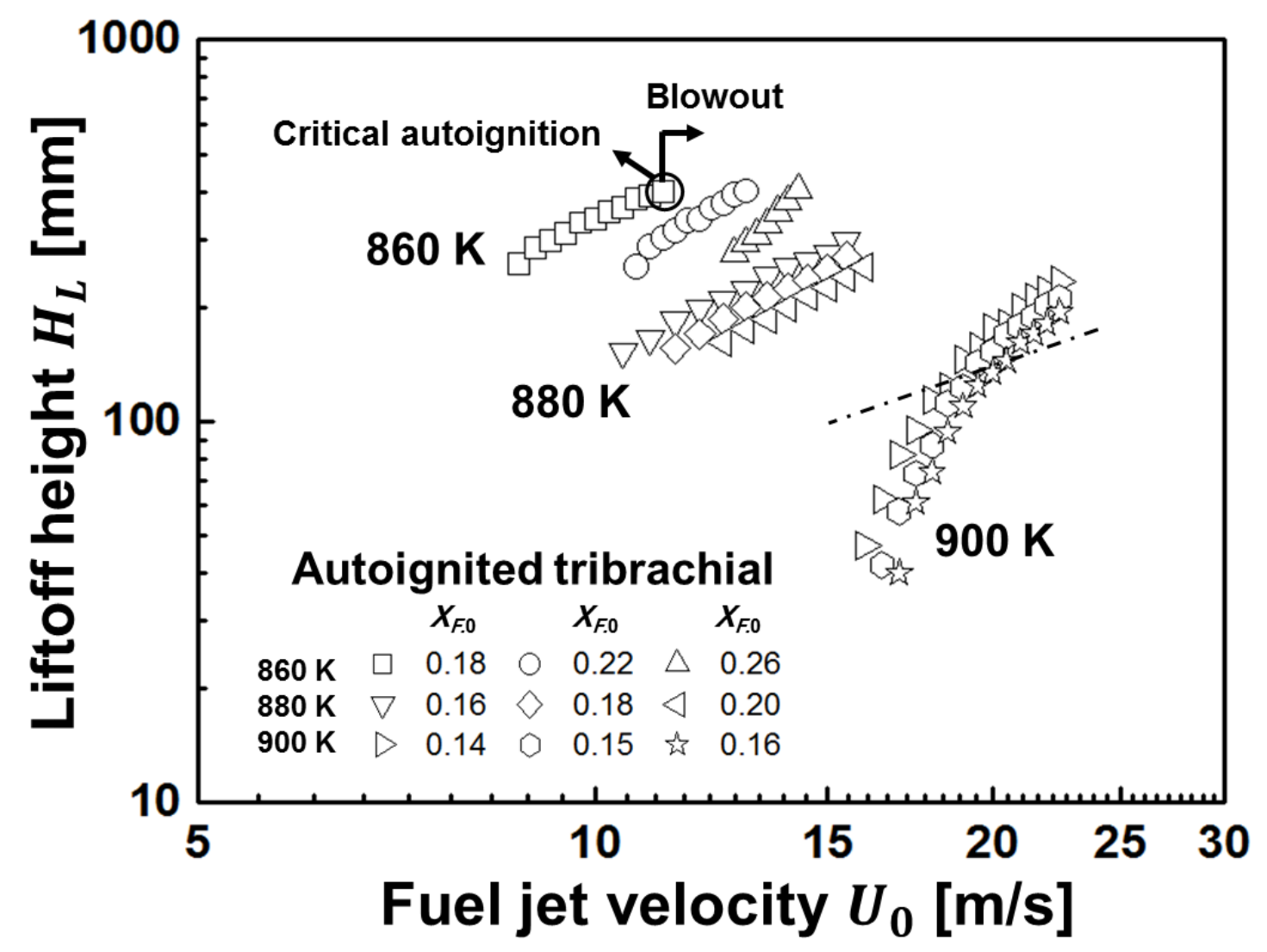

Figure 4. Liftoff height with jet velocity for autoignited lifted flames with tribrachial edges at several initial temperatures and fuel mole fractions.

While at $900 \mathrm{~K}$, the results show somewhat different behavior. As the jet velocity decreases, the liftoff height behavior at relatively small jet velocity deviates from the linear trend in the high jet velocity case, having smaller liftoff height from the extrapolated heights from the case for the high jet velocity data. This deviation may be attributed to two factors as fuel pyrolysis 
or different flame stabilization modes, which will be elaborated later. As the initial temperature or fuel mole fraction increases, the liftoff height decreases due to shorter ignition delay time as elucidated previously for various fuels in the autoignition regime [22-26]. Also, the result shows that the slopes vary depending on the initial temperature and fuel mole fraction. This point will be further discussed later.

A critical autoignition phenomena have been observed previously for gaseous fuels near flame blowout conditions in the autoignition regime $[22,23]$. As an autoignited lifted flame approaches a blowout condition, a repetitive extinction and re-ignition can be observed. This behavior was attributed to the interaction between the buoyancy-induced axial convection and chemical autoignition processes. That is, as an autoignition occurs, the generating flame induces enhanced buoyant convection toward the downstream thus increasing local convection, leading to a blowout. Subsequently, as buoyant convection decreases, the mixture again autoignites and this process repeats.

In such a case, autoignition point can be reasonably accurately measured. Note, however, that for a stationary autoignited lifted flame away from the critical autoignition condition, once autoignition occurs, the flame can propagate upstream and stabilize as a stationary lifted flame, such that autoignition point cannot be measured accurately. Such a behavior was confirmed through a simulation for methane autoignited flame in coflow jets [44], as well as for propane in an experimental environment allowing flow perturbation [22].

The autoignition heights of DME for the critical autoignition cases have been measured and subsequently the characteristic flow time $t_{\text {flow }}=H_{\mathrm{L}} / U_{0}$ can be obtained. This can be related to an adiabatic ignition delay time $t_{\mathrm{ig}, \text { ad, }}$, which can be calculated using the CHEMKIN-Pro software [45] by adopting a skeletal kinetic mechanism for DME proposed by Bhagatwala et al. [16], along with other kinetic mechanisms [15,17-21]. Note that based on the twodimensional thermal explosion theory considering heat loss effect during autoignition process [46], the relation $t_{\text {flow }} \sim t_{\text {ig,ad }}^{2}$ has been derived and experimentally substantiated for gaseous 
fuels in axisymmetric jets [22,23]. The physical reason has been explained based on time scales, where the characteristic heat generation time is $t_{\text {ig,ad. }}$ This is balanced with the heat loss time scale $t_{\text {loss. }}$ In a jet, the heat loss time scale is a diffusion time scale which is the square-root of the convection time $t_{\text {flow }}$. Thus, the balance of these two time scales results in $t_{\text {flow }} \sim t_{\text {ig,ad }}^{2}$.

Such a relation is tested here between the characteristic flow time and the square of the adiabatic ignition delay time for the critical autoignition cases at several initial temperatures and fuel mole fractions. The result is shown in Fig. 5 with the Bhagatwala et al. [16] mechanism. A linear correlation is successfully exhibited and the best fit is $t_{\text {flow }}[\mathrm{s}]=-0.00494+0.11069$ $t_{\mathrm{ig}, \text { ad }}^{2}\left[\mathrm{~s}^{2}\right]$ with a correlation coefficient $R^{2}=0.985$. Note that such correlations were also successful with the mechanism [15], however other mechanisms [17-21] tested were not satisfactory.

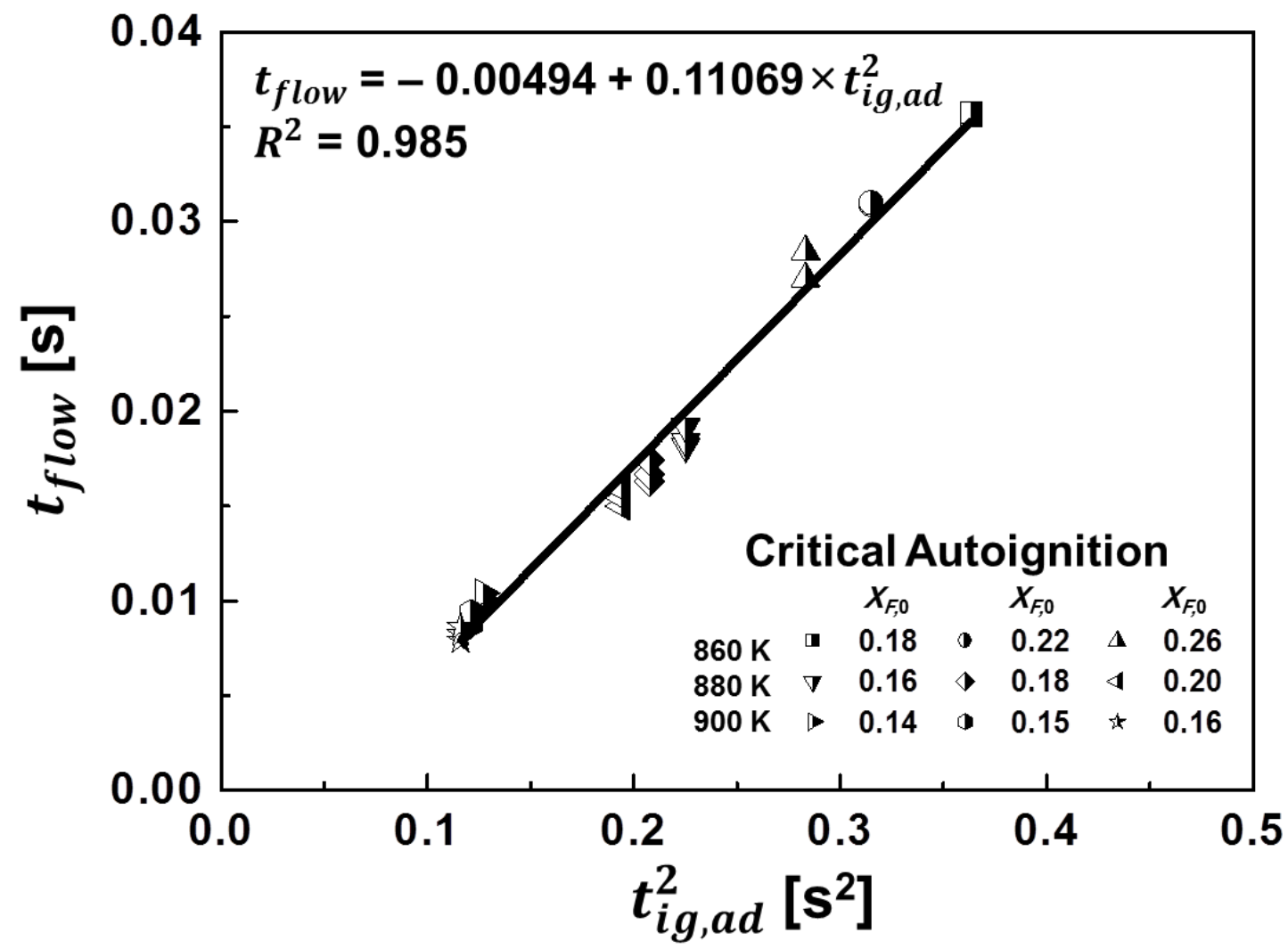

Figure 5. Correlations of convective flow time with calculated adiabatic ignition delay time at critical autoignition cases for autoignited flames with tribrachial edges.

When the fuel jet velocity decreases from the critical autoignition condition, stable 
autoignited DME lifted flames with tribrachial edge are observed (Fig. 4). As mentioned, in steady-state experiments, autoignition position cannot be pin-pointed, however, ignition delay time could still play an important role. For gaseous hydrocarbon fuels [22,23], correlations of liftoff height with calculated adiabatic ignition delay time were successful in the autoignition regime with tribrachial edge structure as $H_{L} \propto\left(U_{0} t_{i g, a d}^{2}\right)^{n}$, where $n$ is a constant. Note that for non-autoignited lifted flames, successful correlations were obtained when the jet velocity is scaled with a stoichiometric laminar burning velocity $\left.S_{L}^{o}\right|_{s t}$ as $H_{L} \propto U_{0} /\left.S_{L}^{o}\right|_{s t}$, emphasizing the role of the propagation speed of tribrachial edge flame, which depends sensitively on $\left.S_{L}^{o}\right|_{s t}$ [22-26].

The liftoff height data in Fig. 4 for the autoignited flames with tribrachial edge is correlated with $\left(U_{0} t_{i g, a d}^{2}\right)^{n}$ in Fig. 6 , where the data in the oval region at $900 \mathrm{~K}$ cases at relatively small jet velocities are excluded in the correlation and are marked as open symbols. The best fit is

$$
H_{\mathrm{L}}[\mathrm{mm}]=35.73\left(U_{0} t_{i g, a d}^{2}\right)^{1.71}[\mathrm{~m}-\mathrm{s}]^{1.71}\left(R^{2}=0.974\right) .
$$

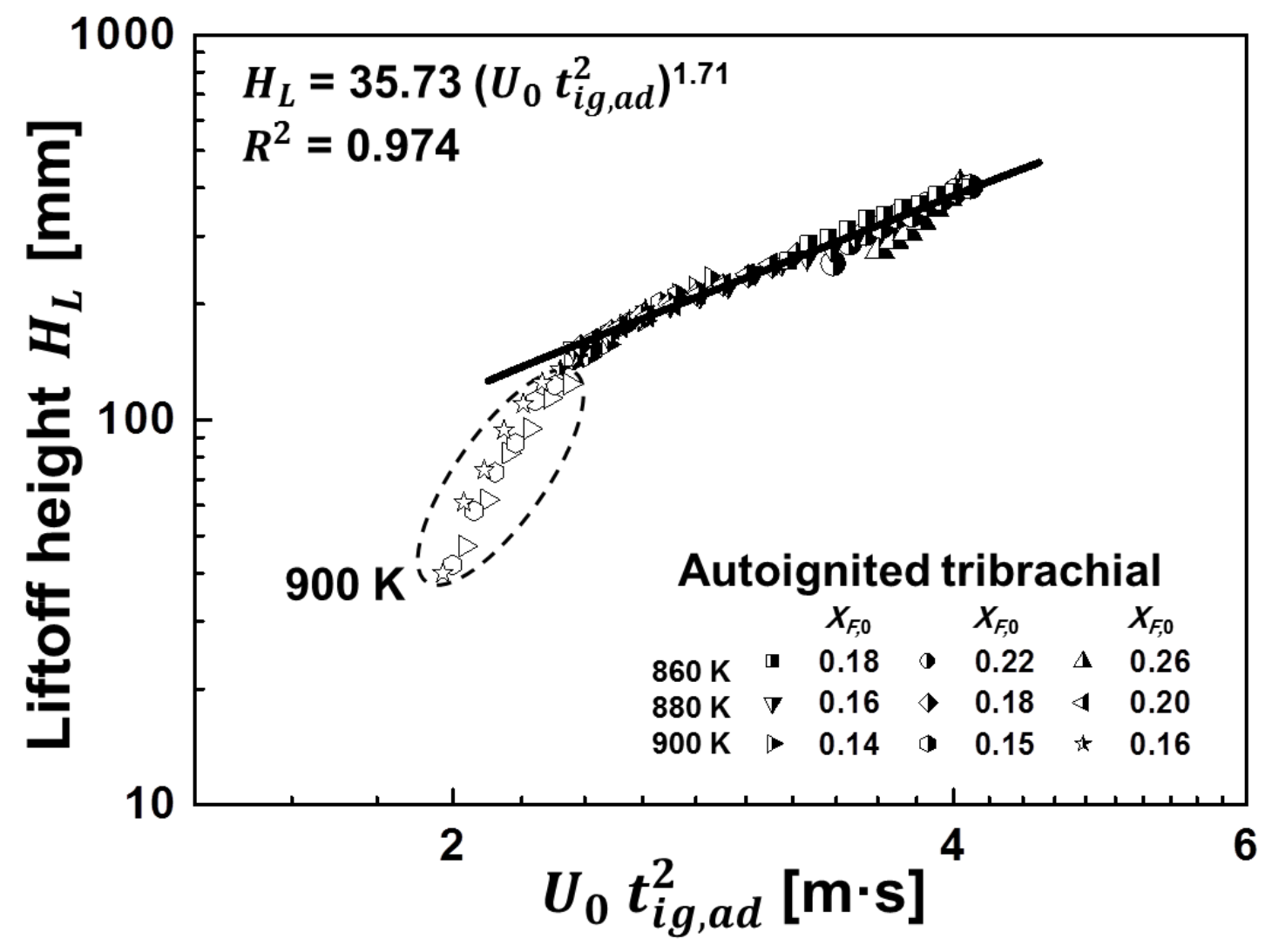


Figure 6. Correlation of liftoff height with jet velocity and calculated adiabatic ignition delay time for autoignited flames with tribrachial edges.

The deviation from the above correlation at $T_{0}=900 \mathrm{~K}$ for relatively small jet velocities is investigated. A first potential reason considered for the deviation is a fuel pyrolysis effect during the passage of fuel through the heated fuel tube before ejecting from the nozzle. The reason being that is the deviation occurring at high temperature $(900 \mathrm{~K})$ and small jet velocity. Considering the temperature sensitive Arrhenius reaction, a pyrolysis effect could be large at high temperature. A smaller jet velocity corresponds to a longer residence time passing through the fuel tube, amplifying the pyrolysis effect. The CHEMKIN-Pro software [45] with the skeletal mechanism [16] is utilized in calculating the fuel pyrolysis effect.

An unsteady homogeneous fuel pyrolysis process is analyzed for diluted DME with nitrogen. Figure 7 shows the variations of species mole fractions as a function of the residence time $t_{\mathrm{res}}$ at $T_{0}=900 \mathrm{~K}$ and $X_{\mathrm{F}, 0}=0.16$. During the early phase of pyrolysis, DME first breaks down into methane and formaldehyde as $\mathrm{CH}_{3}-\mathrm{O}-\mathrm{CH}_{3} \rightarrow \mathrm{CH}_{4}+\mathrm{CH}_{2} \mathrm{O}$. Subsequently, $\mathrm{CO}$ and $\mathrm{H}_{2}$ are formed from $\mathrm{CH}_{2} \mathrm{O}$. After a sufficiently long time, the pyrolysis product of DME becomes $\mathrm{CH}_{3}-\mathrm{O}-\mathrm{CH}_{3} \rightarrow \mathrm{CH}_{4}+\mathrm{CO}+\mathrm{H}_{2}$. Formaldehyde is known to be an excellent candidate as an ignition improver [47,48], much more effective than DME as an ignition improver [2-6], when mixing small amount to a fuel that is difficult to autoignite, such as methane $[47,48]$. Therefore, as $\mathrm{CH}_{2} \mathrm{O}$ is produced through fuel pyrolysis, an effective ignition delay time may be decreased. 


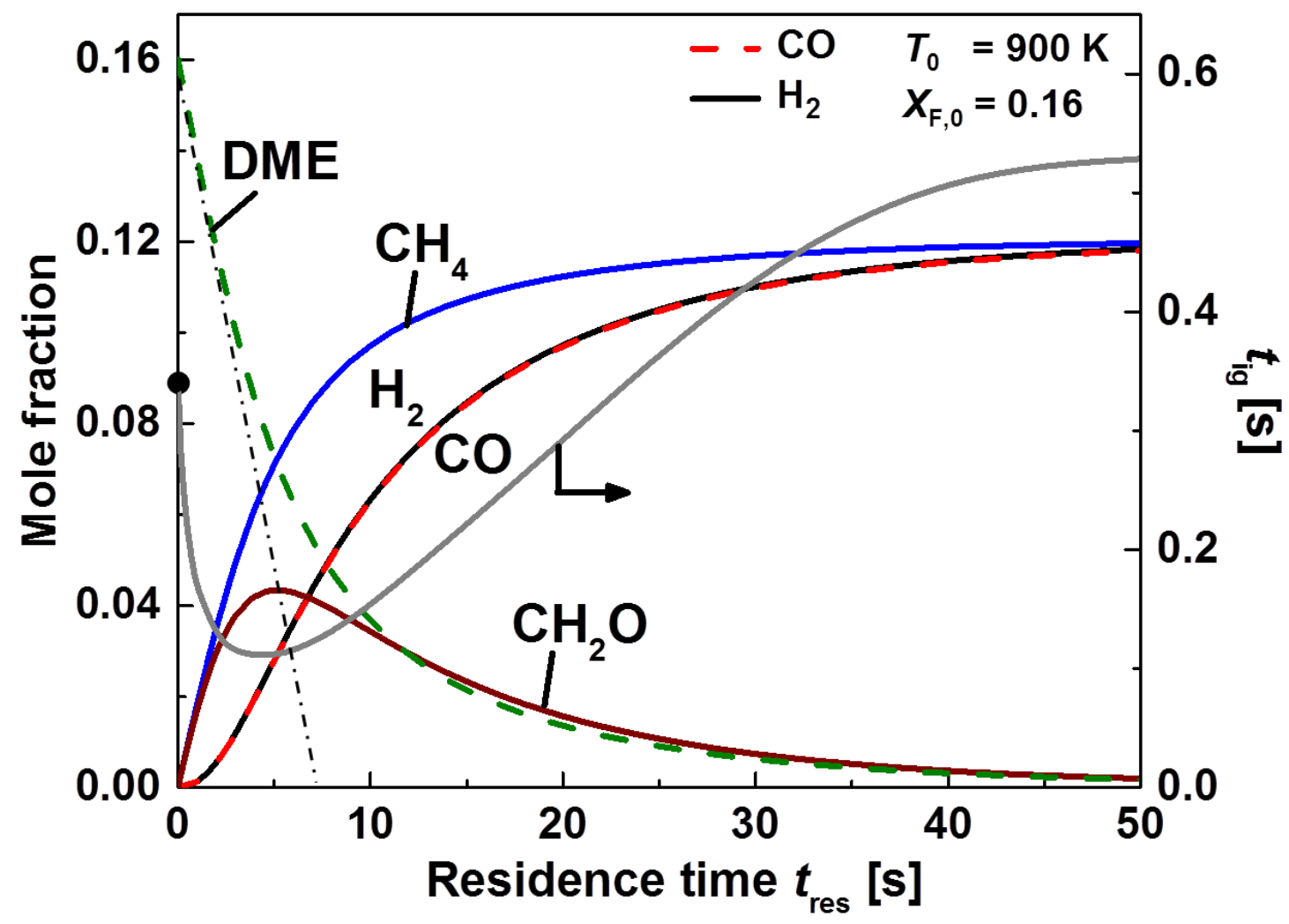

Figure 7. Unsteady fuel pyrolysis process for autoignited lifted flame with tribrachial edge $\left(T_{0}\right.$ $\left.=900 \mathrm{~K}, X_{\mathrm{F}, 0}=0.16\right)$.

In this regard, ignition delay times are calculated by using the temporal pyrolysis products as an initial condition. The result is plotted in Fig. 7 (gray solid line) as a function of time. In terms of the residence time, the ignition delay time initially decreases sharply with the accumulation of $\mathrm{CH}_{2} \mathrm{O}$, and as $\mathrm{CH}_{2} \mathrm{O}$ transforms to $\mathrm{CO}+\mathrm{H}_{2}$, the delay time increases even over the value of non-pyrolized DME at $t_{\text {res }}=0$.

A typical residence time of fuel in the heated fuel tube is $\mathrm{O}(0.1 \mathrm{~s})$ for $U_{0}=\mathrm{O}(10 \mathrm{~m} / \mathrm{s})$ at $T_{0}$ $=900 \mathrm{~K}$ (Fig. 4). For the mixture at $t_{\mathrm{res}}=0.1 \mathrm{~s}, t_{\mathrm{ig}}$ becomes $0.29 \mathrm{~s}$, decreased $15 \%$ from that for $t_{\mathrm{ig}}=0.34 \mathrm{~s}$ for the initial mixture $\left(t_{\mathrm{res}}=0\right)$. As the jet velocity decreases, thereby increasing the residence time, the fuel pyrolysis of DME decreases the ignition delay time, which could decrease the liftoff height. However, this decrease in the ignition delay time by fuel pyrolysis cannot fully explain the rapid decrease in the liftoff height as the jet velocity decreases at $T_{0}=$ $900 \mathrm{~K}$ in Fig. 4, e.g., as $U_{0}$ decreases from 19 to $16 \mathrm{~m} / \mathrm{s}$ (thereby $16 \%$ decrease in residence 
time), $H_{\mathrm{L}}$ decreases from 110 to $40 \mathrm{~mm}$ at $900 \mathrm{~K}$ (55\% decrease). The result, however, suggests that fuel pyrolysis effect needs to be considered in numerical simulation for DME. Note that the characteristic pyrolysis time (determined from the slope of fuel mole fraction at $t_{\text {res }}=0$, corresponding to the maximum slope represented by the dash-dot line) is $7.38 \mathrm{~s}$ for DME as compared with $287 \mathrm{~s}$ for propane.

Another possible reason for the bending behavior in Fig. 4 at $900 \mathrm{~K}$ is based on the two lifted flame stabilization modes. A jet flow can be divided into two regions [25,49,50]; (1) farfield developed region and (2) near-field developing region. For the present autoignited lifted flames, the temperature rise up to the flame zone is small such that the cold jet theory [51] can be applied, from which the developing region length has been estimated for free jets. The axial velocity along the centerline is $U_{\mathrm{CL}}=U_{0}^{2} d^{2} /(8 v x)$, where $v$ is the kinematic viscosity, $d$ is the inner diameter of the fuel nozzle, and $x$ is the axial distance. This centerline velocity $U_{\mathrm{CL}}$ should be at least smaller than the maximum fuel jet velocity, $2 U_{0}$, at the nozzle exit, considering a fully developed Poiseuille flow in the fuel nozzle. This criterion can be expressed as $U_{0}^{2} d^{2} /(8 v x)=2 U_{0}$ and rearranged to $x / d>\mathrm{Re} / 16$. This criterion is marked as the dash-dot line. It is clear that the bending behavior at $900 \mathrm{~K}$ can be attributed to the two different modes of flame stabilization.

\subsection{Liftoff heights of autoignited flames with mild combustion}

Figure 8 shows the behavior of the liftoff height with jet velocity at several initial temperatures and fuel mole fractions for the autoignited lifted flames with mild combustion for the fuels highly diluted with nitrogen. The overall behavior is quite different from the experimental results for single component hydrocarbon gaseous fuels [22-23], where the liftoff height in the mild combustion case generally increased with jet velocity. However, for the present DME fuel, the liftoff behavior can be categorized into three regimes. For example, at $T_{0}=900 \mathrm{~K}$ and $X_{\mathrm{F}, 0}=0.044$, for relatively high jet velocity regime I (marked as the solid line), 
the liftoff height increases with the jet velocity, exhibiting a typical trend in the mild combustion regime. In the intermediate jet velocity regime II, the liftoff height behavior deviates from the trend in the high jet velocity regime (dash-dot line). This can also be explained based on the two modes of flame stabilization in the developing and developed regions, whose criteria is marked as the thin dash-dot line.

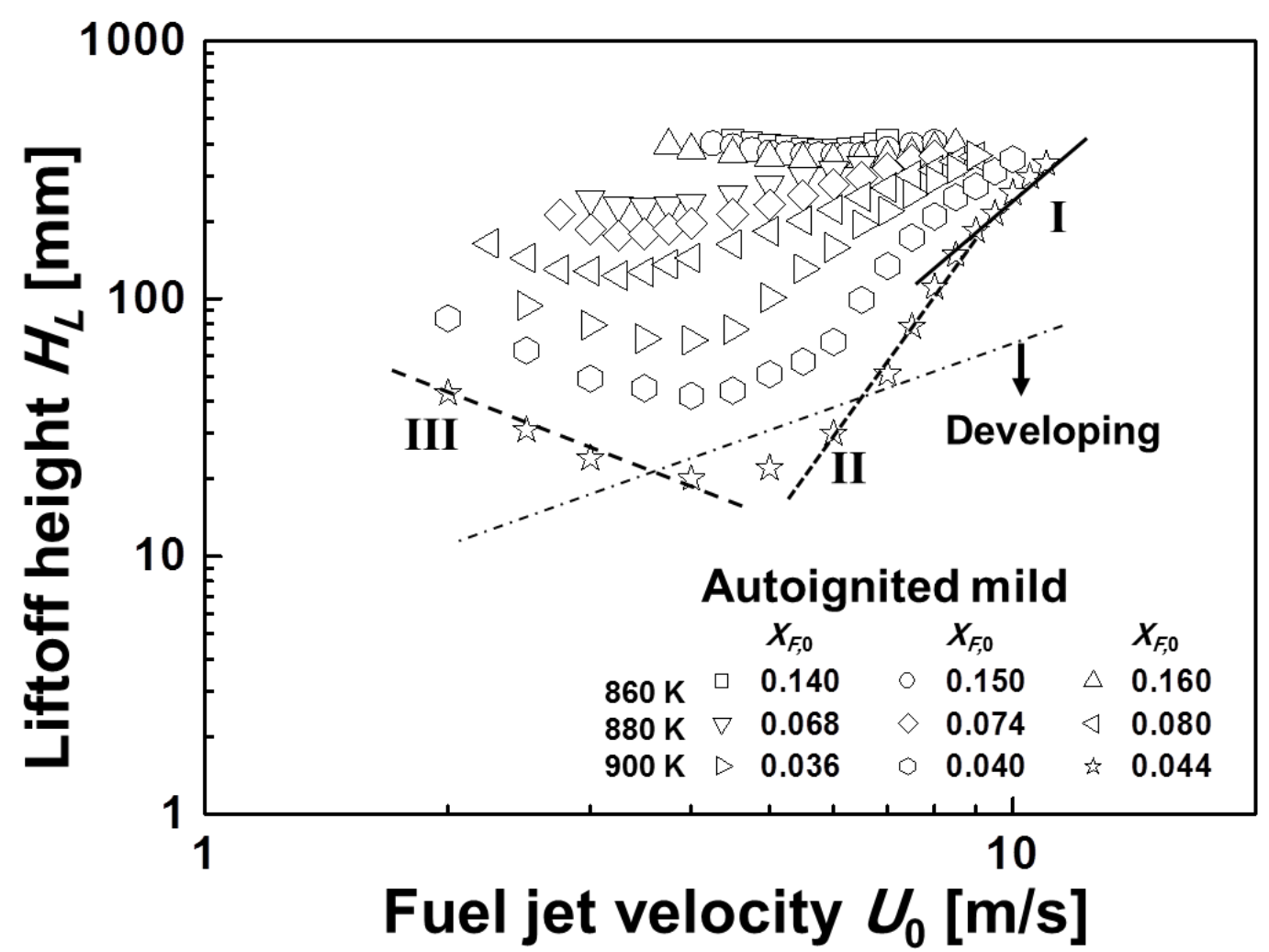

Figure 8. Liftoff height with jet velocity for autoignited lifted flames with mild combustion at several initial temperatures and fuel mole fractions.

It is interesting to note that in the small jet velocity regime III (dashed line), the liftoff height decreases with jet velocity. Such a non-monotonic behavior (decreasing then increasing with jet velocity) was previously observed for autoignited lifted flames of the binary fuel mixtures of $\mathrm{CH}_{4} / \mathrm{H}_{2}[24]$ and $\mathrm{CO} / \mathrm{H}_{2}$ [40], where such a behavior was partially attributed to the differential diffusion since the mass diffusivity of hydrogen is much larger than either $\mathrm{CO}$ or methane. While the detailed mechanism is yet to be identified. Note, however, such behavior was not observed for the single component hydrocarbon fuels [22,23] of methane, ethane, 
propane and n-butane.

This decreasing behavior in liftoff height for the DME with increasing jet velocity (negative slope) cannot be explained based on the previously discussed fuel pyrolysis effect, since such effect could result in a higher positive slope. Instead, it could be partially explained based on unique partial oxidation characteristics of DME fuel. Note that recent simulation for methane autoignition in a coflow jet [44] demonstrated that the kinetic structure of a mild combustion behavior in a jet mixing layer can be reasonably resembles that of the transient homogeneous autoignition behavior of a certain lean mixture of fuel/air, when plotted various species profiles in terms of temperature increase by heat release [44]. In this regard, we have calculated the homogeneous autoignition process of DME/air mixture for $X_{\mathrm{F}, 0}=0.044$. A stoichiometric case was selected since a reasonable lean mixture cannot be estimated. For a comparison, the stoichiometric propane/air mixture for $X_{\mathrm{F}, 0}=0.029$ is also calculated. These fuel mole fractions are selected to have the same adiabatic flame temperatures for both the DME and propane.

Figure 9 shows the profiles of major species and temperature (top), and intermediate species and heat release rate (bottom) with time $t$ for the transient homogeneous autoignition process. The vertical dotted lines mark different horizontal scales to show the behavior in the induction time period and near the thermal runaway period more clearly. The DME fuel exhibits two-stage ignition behavior, having two peaks in the heat release rate with the first peak at $t=$ $0.6225 \mathrm{~s}$, which is marked as $\tau_{\mathrm{g}, 1}$. While the propane fuel shows only single-stage ignition behavior. As mentioned previously, the adiabatic flame temperatures for the DME and propane are similar. While the total ignition delay time for the DME is $\tau_{\mathrm{gg}}=0.627 \mathrm{~s}$, which is much shorter than that for the propane of $14.32 \mathrm{~s}$. 

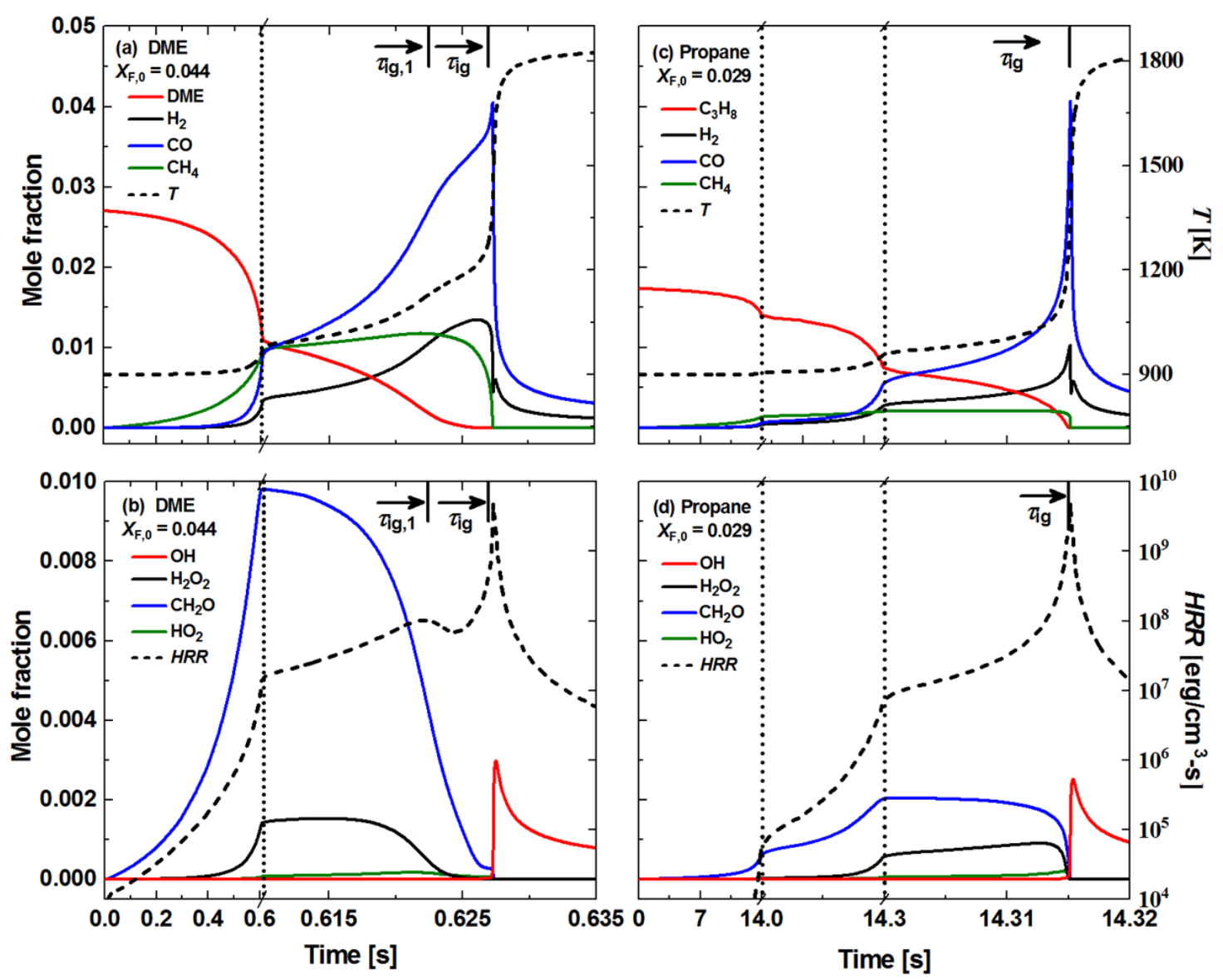

Figure 9. Species mole fraction, temperature, and heat release rate profiles of DME (left) and propane (right) in 0-D autoignition process (vertical dotted lines indicate different horizontal scales).

The DME mole fraction decreases relatively rapidly in the induction time region of $t<0.6$ $\mathrm{s}$ (a), as compared with propane for $t<14 \mathrm{~s}$ (b). The consumption of DME leads to the production of $\mathrm{CH}_{4}, \mathrm{CH}_{2} \mathrm{O}, \mathrm{CO}$ and $\mathrm{H}_{2}$ and their concentrations are appreciable during the induction period, where the temperature change is small. Whereas there are small increases for these concentrations for the propane case. For the DME case, $\mathrm{CH}_{4}$ is produced with higher concentration than $\mathrm{H}_{2}$ initially. Then, $\mathrm{H}_{2}$ becomes higher prior to ignition. The peaks of $\mathrm{CO}$ for both fuels are similar and exist at the thermal runaway. The concentration of $\mathrm{CH}_{2} \mathrm{O}$ is much higher for the DME than the propane. This can be attributed to the maxima of $\mathrm{CH}_{2} \mathrm{O}$ occurring along the centerline in Fig. 3. $\mathrm{H}_{2} \mathrm{O}_{2}$ is also an important intermediate species in autoignition. It is produced early, but then vanishes near the $1^{\text {st }}$-stage ignition time for the DME and the main 
ignition time for the propane. The formation of $\mathrm{OH}$ radical is always very near the ignition incident, indicating high temperature kinetics.

As mentioned, in the numerical simulation for the autoignited lifted flames of methane [44], the kinetic structure in terms of various concentrations as a function of temperature rise in the mixing layer reasonably follows the transient homogeneous autoignition process with time. The existence of $\mathrm{CH}_{4}, \mathrm{H}_{2}$ and $\mathrm{CO}$ with appreciable amount during the induction period for the DME implies that for the autoignited lifted DME flames, such species exist in appreciable amounts in the upstream region from the flame in the mixing layer. This could partly explain the reason why DME flames exhibit decreasing liftoff height behavior for the autoignited mild combustion case, similar to the behavior observed for the binary fuel mixture flames of $\mathrm{CH}_{4} / \mathrm{H}_{2}$ [24] and $\mathrm{CO} / \mathrm{H}_{2}$ [40]. Another possible reason for such non-monotonic behavior may be attributed to NTC behavior. Although kinetic mechanisms are typically validated at high pressures with short ignition delay times due to limited available time in shock tubes, we have tested the NTC behavior at the atmospheric pressure. The NTC behavior was predicted below $850 \mathrm{~K}$, close to the experimental temperature range over $860 \mathrm{~K}$, where the nonmonotonic behavior was observed. While NTC behavior is typically observed by varying temperature at a specified pressure, the change of jet velocity (residence time) could modify the NTC behavior $[32,33]$. Thus, future research is needed to clarify the effects of partial oxidation and NTC behavior on the decreasing liftoff height behavior with jet velocity. It is interesting to note that large hydrocarbons such as n-heptane and iso-octane are expected to form $\mathrm{CH}_{4} / \mathrm{CO} / \mathrm{H}_{2}$ through partial oxidation while not exhibiting such non-monotonic liftoff height behavior [22.23]. In this regard, although not shown, we have tested the partial oxidation characteristics of these two fuels at $980 \mathrm{~K}$, where an autoignited mild combustion was observed. A notable difference as compared with DME case is that the production of $\mathrm{CH}_{4}$ during partial oxidation is small (mole fraction of $\mathrm{CH}_{4}$ is even smaller than that of $\mathrm{H}_{2}$ ), while the DME case has exhibited the largest mole fraction of $\mathrm{CH}_{4}$ among $\mathrm{CH}_{4} / \mathrm{CO} / \mathrm{H}_{2}$. However, this does not fully 
explain why non-monotonic behavior was not observed for such large hydrocarbon fuels, since $\mathrm{CO}$ is produced appreciable amount over $\mathrm{H}_{2}$. A future study is needed to fully understand such behavior.

Such decreasing behavior in autoignited liftoff height with jet velocity can also be observed at lower temperatures at 860 and $880 \mathrm{~K}$ in Fig. 8 . The decreasing behavior is much less conspicuous, partly attributed to the temperature sensitivity of partial oxidation. For single component gaseous fuels in the autoignited lifted flame with mild combustion, the liftoff heights were successfully correlated in terms of $U_{0} t_{i g, a d}^{2} Y_{F, 0}$, while such correlation was unsuccessful for the DME fuel because of the non-monotonic behavior described above. Detailed understanding of such liftoff height behavior requires a numerical simulation, which will be our future study.

The present experiment at the atmospheric pressure condition does not show multi-brachial flame structure. At a high pressure in the numerical simulations [32-34], the methoxymethylperoxy radical $\left(\mathrm{CH}_{3} \mathrm{OCH}_{2} \mathrm{O}_{2}\right)$ played an important role for the multi-brachial flame structure. Although not shown, the concentration of this radical in our zero-dimensional simulation at $1 \mathrm{~atm}$ is several orders of magnitude smaller than that at $40 \mathrm{~atm}$.

\section{Concluding Remarks}

The autoignition characteristics of nonpremixed jet flames of DME have been studied experimentally at elevated temperatures. Formaldehyde PLIF was measured for various flames. For autoignited lifted flames, the formaldehyde profile was observed between the flame edge and the fuel nozzle indicating the autoignition-controlled regime where chemical kinetics play important role on lifted flame stabilization. While for non-autoignited lifted flames, formaldehyde was formed only near the flame edge.

Two autoignited lifted flame structures were observed including the tribrachial edge and the mild combustion. Critical autoignition phenomenon was observed near a blowout condition. 
A successful correlation between the characteristic flow time of lift-off height divided by jet velocity and the square of adiabatic ignition delay time was obtained for autoignited lifted flames with tribrachial edge.

When the fuel was highly diluted, an autoignited lifted flame with mild combustion was stabilized with its weak luminosity. A non-monotonic behavior of lift-off height with jet velocity was observed, similar to the cases of binary fuel mixtures of $\mathrm{CH}_{4} / \mathrm{H}_{2}$ and $\mathrm{CO} / \mathrm{H}_{2}$. A transient homogeneous autoignition analysis suggested that DME partial oxidation generates appreciable amounts of $\mathrm{CH}_{4}, \mathrm{CO}$ and $\mathrm{H}_{2}$ prior to autoignition such that the flame edge could experience effectively mixture fuels in the upstream. A numerical study is required to understand the non-linear behavior in detail, which will be our future study.

\section{Acknowledgment}

This work was supported by King Abdullah University of Science and Technology (KAUST). 


\section{References}

[1] C. Arcoumanis, C. Bae, R. Crookes, E. Kinoshita. The potential of di-methyl ether (DME) as an alternative fuel for compression-ignition engines: A review. Fuel 87 (2008) 1014-1030

[2] V.I. Golovitchev, J. Chomiak. Evaluation of Ignition Improvers for Methane Autoignition. Combust. Sci. Tech. 135 (1998) 31-47.

[3] Y. Tan, C.G. Fotache, C.K. Law. Effects of NO on the Ignition of Hydrogen and Hydrocarbons by Heated Counterflowing Air. Combust. Flame 119 (1999) 346-355.

[4] Z. Chen, X. Qin, Y. Ju, Z. Zhao, M. Chaos, F.L. Dryer. High temperature ignition and combustion enhancement by dimethyl ether addition to methane-air mixtures. Proc. Combust. Inst. 31 (2007) 1215-1222

[5] X.L. Zheng, T.F. Lu, C.K. Law, C.K. Westbrook, H.J. Curran. Experimental and computational study of nonpremixed ignition of dimethyl ether in counterflow. Proc. Combust. Inst. 30 (2005) 1101-1109

[6] P. Dai, Z. Chen, S. Chen. Ignition of methane with hydrogen and dimethyl ether addition. Fuel 118 (2014) 1-8

[7] C.K. Law, P. Zhao. NTC-affected ignition in nonpremixed counterflow. Combust. Flame 159 (2012) 1044-1054.

[8] H. Zhang, E.R. Hawkes, J.H. Chen, S. Kook. A numerical study of the autoignition of dimethyl ether with temperature inhomogeneities. Proc. Combust. Inst. 34 (2013) 803-812.

[9] S. Deng, P. Zhao, D. Zhu, C.K. Law. NTC-affected ignition and low-temperature flames in nonpremixed DME/air counterflow. Combust. Flame 161 (2014) 1993-1997.

[10] U. Pfahl, K. Fieweger, G. Adomeit. Self-ignition of diesel-relevant hydrocarbon-air mixtures under engine conditions. Proc. Combust. Inst. 26 (1996) 781-789

[11] G. Mittala, M. Chaosb, C.J. Sunga, F.L. Dryer. Dimethyl ether autoignition in a rapid compression machine: Experiments and chemical kinetic modeling. Fuel Process. Tech. 89 (2008) 1244-1254

[12] C.T. Bowman, D.M. Golden, R.K. Hanson, H. Pitsch, P.D.F. Davidson, A. Bardos, R. Cook, Z. Hong, S. Jampani, G. Pang. Optimization of Synthetic Oxygenated Fuels for Diesel Engines. GCEP Technical Report. (2006)

[13] P. Dagaut, C. Daly, J.M. Simmie, M. Cathonnet. The oxidation and ignition of dimethylether from low to high temperature (500-1600 K): Experiments and kinetic modeling. Proc. Combust. Inst. 27 (1998) 361-369

[14] R.D. Cook, D.F. Davidson, R.K. Hanson. Shock tube measurements of ignition delay times and $\mathrm{OH}$ time-histories in dimethyl ether oxidation. Proc. Combust. Inst. 32 (2009) 189-196

[15] Z. Zhao, M. Chaos, A. Kazakov, F.L. Dryer. Thermal Decomposition Reaction and a Comprehensive Kinetic Model of Dimethyl Ether. Int. J. Chem. Kinet. 10 (2008) 1- 
18.

[16] A. Bhagatwala, Z. Luo, H. Shen, J.A. Sutton, T. Lu, J.H. Chen. Numerical and experimental investigation of turbulent DME jet flames. Proc. Combust. Inst. 35 (2015) 1157-1166

[17] J.C. Princea, F.A.Williams. A short reaction mechanism for the combustion of dimethyl-ether. Combust. Flame. 162 (2015) 3589-3595.

[18] E.W. Kaiser, T.J. Wallington, M.D. Hurley, J. Platz, H.J. Curran , W.J. Pitz, C.K. Westbrook. Experimental and Modeling Study of Premixed Atmospheric-Pressure Dimethyl Ether-Air Flames. J. Phys. Chem. A. 104:35 (2000) 8194-8206.

[19] U. Burke, K.P. Somers, P. O’Toole, C.M. Zinner, N. Marquet, G. Bourque, E.L. Petersen, W.K. Metcalfe, Z. Serinyel, H.J. Curran. An ignition delay and kinetic modeling study of methane, dimethyl ether, and their mixtures at high pressures. Combust. Flame 162 (2015) 315-330.

[20] H. J. Curran, S. L. Fischer, F. L. Dryer. The Reaction Kinetics of Dimethyl Ether. II: Low-Temperature Pyrolysis and Oxidation in Flow Reactors. Int. J. Chem. Kinet. 32 (2000) 741-7591.

[21] W. K. Metcalfe, S. M. Burke, S. S. Ahmed, H. J. Curran. A Hierarchical and Comparative Kinetic Modeling Study of C1-C2 Hydrocarbon and Oxygenated Fuels. Intl. J. Chemical Kinetics 45 (2013) 638-675.

[22] B.C. Choi, K.N. Kim, S.H. Chung. Autoignited laminar lifted flames of propane in coflow jets with tribrachial edge and mild combustion. Combust. Flame 156 (2009) 396-404.

[23] B.C. Choi, S.H. Chung. Autoignited laminar lifted flames of methane, ethylene, ethane, and n-butane jets in coflow air with elevated temperature. Combust. Flame 157 (2010) 2348-2356.

[24] B.C. Choi, S.H. Chung. Autoignited laminar lifted flames of methane/hydrogen mixtures in heated coflow air. Combust. Flame 159 (2012) 1481-1488.

[25] S.K. Choi, S.H. Chung. Autoignited and non-autoignited lifted flames of prevaporized $n$-heptane in coflow jets at elevated temperatures. Combust. Flame 160 (2013) 1717-1724.

[26] S.M. Al-Noman, S.K. Choi, and S.H. Chung. "Autoignition characteristics of laminar lifted jet flames of pre-vaporized iso-octane in heated coflow air". Fuel. 162 (2015) 171-178.

[27] S.K. Choi, S. Al-Noman, S.H. Chung. Simulation of non-autoignited and autoignited laminar nonpremixed jet flames of syngas in heated coflow air. Combust. Sci. Technol., 187 (2015) 132-147.

[28] S.H. Chung, B.J. Lee. On the characteristics of laminar lifted flames in a nonpremixed jet. Combust. Flame 86 (1991) 62-72.

[29] B.J. Lee, S.H. Chung. Stabilization of lifted tribrachial flames in a laminar nonpremixed jet. Combust. Flame 109 (1997) 163-172. 
[30] S.H. Chung. Stabilization, propagation and instability of tribrachial triple flames. Proc. Combust. Inst. 31 (2007) 877-892.

[31] A. Cavaliere, M. Joannon. Mild Combustion. Prog. Energy Combust. Sci. 30 (2004) 329-366.

[32] S. Deng, P. Zhao, M.E. Mueller, C.K. Law. Autoignition-affected stabilization of laminar nonpremixed DME/air coflow flames. Combust. Flame. 162 (2015), 34373445 .

[33] S. Deng, P. Zhao, M.E. Mueller, C.K. Law. Stabilization of laminar nonpremixed DME/air coflow flames at elevated temperatures and pressures. Combust. Flame. 162 (2015) 4471-4478.

[34] A. Krisman, E.R. Hawkes, M. Talei, A. Bhagatwala, J.H. Chen. Polybrachial structures in dimethyl ether edge-flames at negative temperature coefficient conditions. Proc. Combust. Inst. 35 (2015) 999-1006.

[35] C. Brackmann, J. Nygren, X. Bai, Z.S. Li, H. Bladh, B. Axelsson, I. Denbratt, L. Koopmans, P.E. Bengtsson, M. Aldén. Spectrochim. Acta Part a - Mol. Biomol. Spectrosc., 59 (2003), pp. 3347-3356

[36] S.B. Dworkin, A.M. Schaffer, B.C. Connelly, M.B. Long, M.D. Smooke, M.A. Puccio, B. McAndrew, J.H. Miller. Measurements and calculations of formaldehyde concentrations in a methane/N2/air, non-premixed flame: Implications for heat release rate. Proc. Combust. Inst. 32 (2009) 1311-1318.

[37] A. Schneider, J. Mantzaras, R. Bombach, S. Schenker, N. Tylli, P. Jansohn. Laser induced fluorescence of formaldehyde and Raman measurements of major species during partial catalytic oxidation of methane with large $\mathrm{H}_{2} \mathrm{O}$ and $\mathrm{CO}_{2}$ dilution at pressures up to 10 bar. Proc. Combust. Inst. 31 (2007) 1973-1981.

[38] H. Yamada, K. Suzaki, H. Sakanashi, N. Choi, A. Tezaki. Kinetic measurements in homogeneous charge compression of dimethyl ether: role of intermediate formaldehyde controlling chain branching in the low-temperature oxidation mechanism. Combust. Flame 140 (2005) 24-33.

[39] R.L. Gordon, A.R. Masri, E. Mastorakos. Heat release rate as represented by [OH] $\times$ $\left[\mathrm{CH}_{2} \mathrm{O}\right]$ and its role in autoignition. Combust. Theory Model. 13:4 (2009) 645-670.

[40] B.C. Choi, S.H. Chung. Characteristics of autoignited laminar lifted flames in heated coflow jets of carbon monoxide/hydrogen mixtures. Trans. Korean Soc. Mech. Eng. B (in Korean) 36 (2012) 639-646.

[41] J.E. Harrington, K.C. Smyth. Laser-induced fluorescence measurements of formaldehyde in a methane/air diffusion flame. Chem. Phys. Lett. 202 (1993) 196202.

[42] R.L. Gordon, A.R. Masri, E. Mastorakos. Simultaneous Rayleigh temperature, OHand $\mathrm{CH}_{2} \mathrm{O}$-LIF imaging of methane jets in a vitiated coflow. Combust. Flame. 155 (2008) 181-195.

[43] F. Bisetti, S.M. Sarathy, M. Toma, S.H. Chung. Stabilization and structure of nheptane tribrachial flames in axisymmetric laminar jets. Proc. Combust. Inst., 35 
(2015) 1023-1032.

[44] S.M. Al-Noman, S.K. Choi, and S.H. Chung. Numerical Study of Laminar Nonpremixed Methane Flames in Coflow Jets: Autoignited Lifted Flames with Tribrachial Edges and Mild Combustion at High Temperatures. Combust. Flame. 171 (2016) 119-132.

[45] CHEMKIN-PRO Release 15092, Reaction Design Inc., San Diego, CA, 2010.

[46] T. Boddington, C.g. Feng, P. Gray, Thermal explosion and times-to-ignition in systems with distributed temperatures. I. Reactant consumption ignored. Proc. R. Soc. London A 385 (1983) 289-311.

[47] M. Morsy, D. Ahn, S.H. Chung, Pilot injection of DME for ignition of natural gas at dual fuel engine-like conditions. International journal of automotive technology, 7:1 (2006) 1-8.

[48] M. Morsy, S.H. Chung, Effect of additives on ignition of methane at homogeneous charge compression ignition engine-like conditions. Proceedings of the Institution of Mechanical Engineers, Part D: Journal of Automobile Engineering, 221:5 (2007) 605619.

[49] S.H. Won, M.S. Cha, S.H. Chung, B.J. Lee. Lifted flame stabilization in developing and developed regions of coflow jets for highly diluted propane. Proc. Combust. Inst. 28 (2000) 2093-2099.

[50] K.N. Kim, S.H. Won, S.H. Chung. Characteristics of laminar lifted flames in coflow jets with initial temperature variation. Proc. Combust. Inst., 31 (2007), 947-954.

[51] B.J. Lee, J.S. Kim, S.H. Chung. Effect of dilution on the liftoff of non-premixed jet flames. Proc. Combust. Inst. 25 (1994) 1175-1181. 


\section{Figure Captions}

Figure 1. Schematic of experimental setup.

Figure 2. Visible images and $\mathrm{CH}_{2} \mathrm{O}$ PLIF images for non-autoignited and autoignited lifted flames of DME (a-c) and propane (d-f).

Figure 3. Figure 3. Autoignition regimes of DME in terms of initial temperature and fuel mole fraction. Symbols indicate the modes of no-autoignition (No-auto), autoignited tribrachial (A-Tri; solid triangle), autoignited mild (A-Mild; solid circle and cross (outside of measurement range)), transition (from tribrachial to mild combustion; open circle), transition to turbulence(TT; open triangle).

Figure 4. Liftoff height with jet velocity for autoignited lifted flames with tribrachial edges at several initial temperatures and fuel mole fractions.

Figure 5. Correlation of convective flow time with calculated adiabatic ignition delay time at critical autoignition cases for autoignited flames with tribrachial edges.

Figure 6. Correlation of liftoff height with jet velocity and calculated adiabatic ignition delay time for autoignited flames with tribrachial edges.

Figure 7. Unsteady fuel pyrolysis process for autoignited lifted flame with tribrachial edge $\left(T_{0}=900 \mathrm{~K}, X_{\mathrm{F}, 0}=0.16\right)$.

Figure 8. Liftoff height with jet velocity for autoignited lifted flames with mild combustion at several initial temperatures and fuel mole fractions.

Figure 9. Species mole fraction, temperature, and heat release rate profiles of DME (left) and propane (right) in 0-D autoignition process (vertical dotted lines indicate different horizontal scales). 